ПЕТРОСЯНЦ Даниэл Викторович - доцент департамента политологии и массовых коммуникаций Финансового университета при Правительстве РФ (125993, Россия, г. Москва, ГСП-3, Ленинградский пр-кm, 49; dan-basa@yandex.ru)

\title{
СОЦИАЛЬНОЕ НЕРАВЕНСТВО И БЕДНОСТЬ КАК ФАКТОРЫ СДЕРЖИВАНИЯ ДОЛГОСРОЧНОГО ЭКОНОМИЧЕСКОГО POCTA
}

Аннотация. В статье предпринята попытка системно рассмотреть проблему неравенства и бедности в современном российском обществе, провести параллели с зарубежной практикой схожих ситуаций. Автор проводит анализ динамических рядов результатов опросов ВЦИОМа по индексам социального самочувствия и числа публикаций о проблемах бедности в российских СМИ, которые демонстрируют корреляционную зависимость с 2012 по 2018 г. Начиная с IV квартала 2018 г. проблема бедности в CMИ становится все более обсуждаемой и уже не коррелирует с исследованиями ВЦИОМа. Автор предлагает прототипы методических рекомендаций по созданию в обществе предпосылок для снижения неравенства, требующие дальнейших проработок и форсайт-исследований.

Ключевые слова: социальное неравенство, бедность, социальная напряженность, экономический рост, порочный круг бедности, индекс Джинни

$\mathrm{B}$ ыстраиваемая после распада СССР социально-политическая система Российской Федерации пребывает с начала 90-х гг. XX в. в стадии перманентных реформ и никак не приближается к четко выстроенной схеме, соответствующей лучшим образцам ведущих западных государств. Современная Россия ставит перед собой амбициозные, но достижимые цели долгосрочного развития - обеспечение высокого уровня благосостояния населения, закрепление геополитической роли страны как одного из глобальных лидеров, определяющих мировую политическую повестку дня. Однако нарастающие в последние годы разрывы в доходах населения, приводящие как к обогащению наиболее обеспеченной части населения, так и обнищанию наиболее уязвимых социальных групп российского общества, ведут к устойчивым зонам социальной напряженности в стране.

Демонтаж советского социального государства привел к невиданному ранее взлету неравенства в нашей стране. Пока «нижняя часть» общества все глубже погружается в кредитную кабалу, верхушка концентрирует в своих руках немыслимое богатство, которым просто невозможно производительно распорядиться. В России в сентябре 2017 г. к краткосрочным кредитам «от зарплаты до зарплаты», ставка по которым может превышать $700 \%$ в годовом исчислении, прибегали 8,5 млн чел. И эта цифра растет ежегодно.

В указе Президента РФ «О национальных целях и стратегических задачах развития Российской Федерации на период до 2024 года» в качестве одной из национальных целей ставится двукратное снижение бедности за обозначенный период ${ }^{1}$. Нашу страну на пути снижения бедности и обеспечения социального согласия ждут немалые трудности, но именно эта проблема является системной и требующей обязательного демпфирования.

В последнее время активно изучаемые в ходе экономических и социологиче-

\footnotetext{
1 Указ Президента Российской Федерации от 07.05.2018 № 204 «О национальных целях и стратегических задачах развития Российской Федерации на период до 2024 года». Доступ: www. kremlin.ru/acts/bank/43027 (проверено 04.01.2020).
} 
ских исследований проблемы, связанные с дифференциацией уровня жизни, распались на два класса: дифференциация по социальным группам и дифференциация по регионам страны. В свою очередь, эти два класса задач накладываются на экономическую и социальную дифференциацию. Сейчас под стандартные методы измерения экономического и социального неравенства подпадают и уровень душевых инвестиций, и неравномерность налоговых доходов [Балацкий, Саакянц 2006: 122].

При этом многие вопросы остаются нерешенными, более того, похоже, что они вообще не могут быть до конца решены без комплексного системного подхода к определению неравенства и черты бедности. А именно это станет первым шагом к выстраиванию государственных программ преодоления неравенства и бедности (если такие задачи действительно ставятся). Целью статьи не является критический анализ ключевых индикаторов определения бедности и социального расслоения.

Несмотря на очевидные доказательства связи бедности с психологическими факторами, политика борьбы с бедностью обычно не принимает во внимание чувства стыда, отчаяния и социальной растерянности. Усилия по снижению уровня бедности обычно фокусируются на материальных проявлениях нищеты: например, низком уровне доходов или недостаточном образовании. В результате применяемые решения зачастую опираются на идею, что повышение уровня материального богатства или улучшение условий жизни автоматически создаст и нематериальные выгоды, в частности улучшит психологическое состояние людей.

Бедность в России отличается от бедности в развитых и даже в развивающихся странах. Кто попадает в разряд бедных в большинстве случаев? Безработные и представители так называемого андеграунда. А кто беден в России? И безработные, и работающие. Социально нет гарантий, что, даже устроившись на работу, человеку удастся обеспечить себя и свою семью достойным существованием.

Для целого ряда регионов России характерна проблема, известная как «порочный круг бедности». Недостаток капитала ограничивает возможности применения новой техники и современных технологий в производстве. Это порождает низкий уровень производительности труда, который в свою очередь сдерживает рост доходов населения. Низкие доходы означают низкий спрос и отсутствие мотиваций, стимулирующих население откладывать сбережения. В итоге ограниченность финансовых ресурсов и отсутствие стимулов препятствуют инвестированию в физический и человеческий капитал. А это означает, что круг замкнулся, т.е. сохраняющаяся низкая производительность труда порождает низкие доходы и т.д.

Многие современные российские и зарубежные ученые отмечают конвергенцию дифференциации по доходам населения, и это несмотря на то, что различия между российскими регионами остаются значительными и весьма вариабельными. При этом все же в основном неравенство носит внутрирегиональный характер. Оценки регионального коэффициента Джини на основе потребления колеблются от 0,28 во Владимирской обл., Карачаево-Черкесии и Дагестане до более 0,40 в Иркутской обл., Москве и Тюмени. Анализ подушевого потребления домохозяйств показывает: свыше $90 \%$ неравенства имеет внутрирегиональный характер, что согласуется с выводом, что внутрирегиональное неравенство, как правило, выше, чем межрегиональное. Однако следует отметить, что этот показатель в России заметно увеличился по сравнению с прошлым десятилетием. В 1994-2000 гг. всего лишь около 2/3 увеличения 
неравенства были обусловлены внутрирегиональным распределением доходов, а сейчас - около $90 \% 1$.

Каковы же методы создания в обществе предпосылок для снижения неравенства, демпфирования проблем бедности? Или такая задача не стоит на повестке дня?

I. Непрерывная борьба с любыми проявлениями коррупции. Благотворительный фонд One, который занимается проблемой бедности в мире, выступил в 2014 г. с докладом о последствиях коррупции для миллионов людей, которые оказываются в результате на грани нищеты и погибают. По оценкам экспертов организации, каждый год около триллиона долларов выводится из бедных стран. В докладе One говорится, что значительный прогресс в борьбе с бедностью, которого удалось добиться за последние два десятилетия, поставлен под угрозу коррупцией и преступностью. Среди наиболее распространенных методов - отмывание денег и использование подставных «фантомных фирм».

II. Особенно остро проблема бедности стоит перед наиболее социально уязвимой категорией населения - пенсионерами [Соловьев 2014]. Но именно здесь скрыт и еще один парадокс. В части регионов Центральной России, что особенно характерно для сельской местности, именно пенсионные доходы граждан являются основными в целом ряде домохозяйств. Численность таких домохозяйств может достигать $50 \%$ и более по району/региону.

III. Представляется, что у государства есть возможность применить новые измерения в решении проблемы бедности. Существуют различные активы, обладание которыми либо равный доступ к которым в состоянии оказать заметное влияние на радикальное решение проблемы бедности, изменение динамики доходности наиболее необеспеченных домохозяйств, социального статуса, образа жизни и поведения индивидуумов в обществе.

1. Образование, здравоохранение, социальные гарантии, качественные продукты питания и т.П. должны быть доступны всему населению. Необходимо улучшать социальную среду, сводить к минимуму территориальные диспропорции. Это потребует пересмотра формирования региональных трансфертов дотационным регионам с приданием этим траншам целевой социальной адресности.

2. Земля, жилье. Проблема широкая и напрямую не решается, т.к. требует серьезных затрат. Можно вспомнить опыт американских левиттаунов - пригородных поселков, успех которых в 1940-1950-х гг. был обеспечен конвейерным методом строительства. Но отсутствие на российском рынке массовых технологий дешевого жилищного строительства по типу американских коттеджей и блоков квартир делают нишу бюджетного жилья в стране неразвитой. Территория нашей страны позволяет наделять граждан земельными участками, что может стать наглядным примером новых подходов к приватизации с точки зрения доминирующего в обществе представления о справедливости. В принципе опыт уже есть, наиболее яркий пример - «дальневосточный гектар».

3. Развитие малого и среднего предпринимательства. Без пропаганды достижений частного бизнеса и создания рабочих мест нового качества с совершенно другим уровнем дохода, которые позволят добиться одобрения курса проводимых реформ большей частью населения, невозможно надеяться, что модернизация экономики может быть проведена за счет рыночных преобразований.

4. Приватизация - наделение собственностью (в т.ч. через приватизацию

1 Преодоление пространственного неравенства: как снова собрать советский «пазл» в условиях рыночной экономики? Доклад. - Всемирный банк. 24.06.2019. Доступ: http://documents. worldbank.org/curated/en/home (проверено 04.01.2020). 
оставшейся части государственного имущества, земли, природных ресурсов). Коррупция при приватизации капитализирует будущую ренту. Именно это обстоятельство лежит в основе озабоченности общества итогами приватизации. Основной лейтмотив действий властей в этом направлении и в строгих рамках правового поля должен сводиться к тому, чтобы расширить в обществе круг лиц, капитализирующих будущую ренту. Таким образом, формирование долгосрочных отношений в обществе по поводу приватизации может стать дополнительным активом, распределяемым для повышения дохода населения страны.

Следующее звено создания в обществе предпосылок к согласованию коллективных интересов - формирование и развитие среднего класса. Следует понимать, что инерционные представления о среднем классе, оставшиеся со времен СССР, в нынешней системе ценностей не срабатывают. Развитие современных экономик напрямую зависит от роста потребительской активности среднего класса. Следует отметить, что политическая наука не рассматривает средний класс как однородное сообщество, выделяя, например, три его группы: высший, средний и низший средний класс.

Есть множество методик определения и отнесения граждан к этой группе, отметим лишь главное: измерение численности среднего класса нельзя осуществлять исходя только из экономических условий. Не менее важна психология, а точнее, насколько коррелируют выстроенные институты общества с психообщественной инфраструктурой общества на данной территории [Завельский 2009]. В современном Китае удалось создать крупнейший в мире средний класс, его численность превышает 400 млн чел. при общем населении в 1,4 млрд чел. В средний класс китайское Национальное бюро по статистике включает граждан, чьи доходы после уплаты налогов находились на уровне 4009 долл. в $2017 \Gamma^{1}$ В трех крупнейших городских агломерациях восточного Китая - Пекине, Шанхае и Гонконге - ВВП по паритету покупательной способности на душу населения уже достиг уровня Тайваня и Южной Кореи, а жизненные стандарты многих пекинских и шанхайских семей стали сопоставимыми со стандартами состоятельных слоев общества США. В Китае годами выстраиваются социальные лифты, причем не только на бумаге. Ребенок рабочих или жителей сельских районов, поступая в колледж, становится специалистом, ученым и т.п., переходя в другую социальную страту. Его дети уже поступают в университеты как представители среднего класса. Таким образом, обеспечиваются и воспроизводство, и увеличение, и кооптация среднего класса. Ничего нового не предлагается, тем не менее в китайском обществе этот механизм вполне себя оправдал.

С политической точки зрения очень важен фокус освещения деятельности государства и правительства пропагандистски выверенными месседжами. Но на сегодняшний день в России все происходит с точностью до наоборот - фокус этот направлен на негатив. На рис. 1 представлены динамические ряды результатов опросов ВЦИОМа по индексам социального самочувствия и числа публикаций о проблемах бедности в России. На основе анализа рядов можно сделать предположение, что, начиная с IV квартала 2018 г., ситуация с вопросами бедности в нашей стране становится все более сложной и проблемной. С III квартала 2018 г. можно наблюдать существенное увеличение контента публикаций в российских СМИ, посвященных проблемам бедности и их преодолению.

1 Национальное бюро по статистике КНР. 20.09.2019. URL: http://data.stats.gov.cn/english/ index.htm (проверено 04.01.2020). 


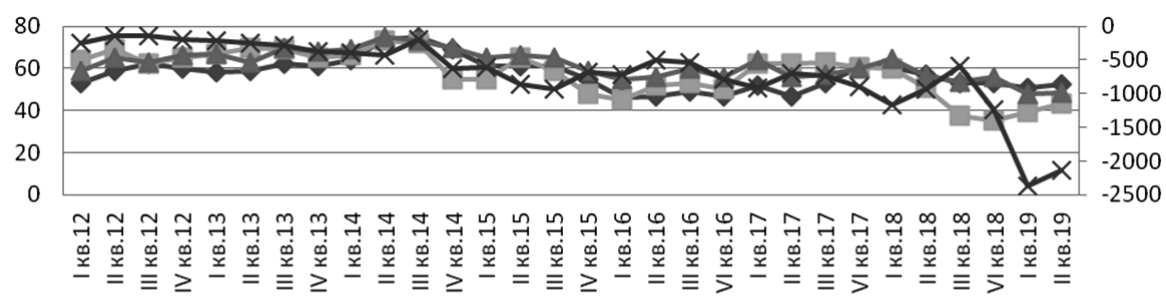

—Индекс «В какой мере Вас устраивает сейчас жизнь, которую Вы ведете?»

- Индекс «Как Вы считаете, через год Вы (Ваша семья) будете жить лучше или хуже, чем сейчас?»

- Индекс «Как бы Вы оценили в настоящее время материальное положение Вашей семьи?»

$\longleftarrow$ СКАН - проблемы бедности

Составлено по: База российских СМИ SCAN-Интерфакс. 20.09.2019. Доступ: http://new.scaninterfax.ru; ВЦИОМ. Доступ: https://wciom.ru/index.php?id=223 (проверено 15.01.2020).

Рисунок 1. Сравнительный анализ динамики результатов опросов ВЦИОМа по индексам социального самочувствия и числа публикаций о проблемах бедности в России

Особенность социальной политики в промышленно развитых странах заключается в том, что она направлена не просто на защиту человека от социальных рисков (утрата дохода в связи с болезнью, инвалидностью и старостью), но и на недопущение резкого материального и социального неравенства, на обеспечение достаточно высокого уровня социальной поддержки и помощи нуждающимся слоям населения, на предоставление гражданам доступа к качественным здравоохранению и образованию.

Сегодня среди главных проблем российского общества можно отметить дефицит доверия, социальную дистанцию между обществом и властью, рассинхронизацию интересов различных общественных страт. Преодоление бедности и снижение неравенства в обществе - задача не только экономическая, но социальная, политическая. Недоверие в отношениях между элитами и остальным обществом создает в социуме «зоны напряжения», преодоление которых возможно в первую очередь при создании социально-экономических условий, которые могут стать отправной точкой для уменьшения социального неравенства и бедности у нас в стране.

\footnotetext{
Статья подготовлена по результатам исследований, выполненных за счет бюджетных средств по государственному заданию Финуниверситету по теме «Технологические, структурные и социальные факторы долгосрочного экономического роста».
}

\section{Список литературы}

Балацкий Е.В., Саакянц К.М. 2006. Индексы социального неравенства. - Мониторинг общественного мнения: экономические и социальные перемены. № 2(78). С. 122-128.

Завельский М.Г. 2009. Закономерности хозяйства. - Труды Института системного анализа РАН. Т. 47. С. 4-36. 
Соловьев А.К. 2014. Проблема преодоления бедности пенсионеров - ключевая задача государства и общества современной России. - Экономические $и$ социальные перемены: факты, тенденции, прогноз. № 5(35). С. 143-155.

PETROSYANTS Daniel Viktorovich, Associate Professor at the Department of Political Science and Mass Communication, Financial University under the Government of the Russian Federation (49 Leningradsky Ave, GSP-3, Moscow, Russia, 125993; dan-basa@yandex.ru)

\title{
SOCIAL INEQUALITY AND POVERTY AS FACTORS OF CONTINUING LONG-TERM ECONOMIC GROWTH
}

\begin{abstract}
The article attempts to consider systematically the problem of inequality and poverty in modern Russian society, to draw parallels with the foreign practice of similar situations. The author analyzes the time series of the results of Russian Public Opinion Research Center (VCIOM) polls on social well-being indices and the number of publications on poverty issues in the Russian media that show a correlation between 2012 and 2018. Since the $4^{\text {th }}$ quarter of 2018, the problem of poverty in the media has become discussed more and more and no longer correlates with VCIOM's studies. In addition, the author proposes prototypes of methodological recommendations on creating prerequisites in society for reducing inequality, requiring further study and foresight research.
\end{abstract}

Keywords: social inequality, poverty, social tension, economic growth, vicious cycle of poverty, Ginny index 